\title{
Optimization of subcritical water extraction of phenolic compounds from Ziziphus jujuba using response surface methodology: evaluation of thermal stability and antioxidant activity
}

Razieh Niazmand ${ }^{1 *} \mathbb{D}$, Mostafa Shahidi Noghabi ${ }^{1}$ and Azam Niazmand ${ }^{2}$

\begin{abstract}
Background: The jujube is mainly grown in the subtropical and tropical regions of Asia. Due to owning bioactive compounds such as polyphenols, it was considered as medicinal and nutritional plant in traditional medicine. This study aimed to extract phenolic compounds from Ziziphus jujuba using subcritical water (SCW) process. The possible combinations of temperature, time, and fruit-to-solvent ratio were investigated using response surface methodology.

Results: The total phenolic compounds (TPC) and radical scavenging capacity (RSC) of $975.94 \mathrm{mg} / \mathrm{g}$ and 53.98\%, respectively, were recovered at optimum extraction conditions $\left(170^{\circ} \mathrm{C}, 74.49 \mathrm{~min}\right.$, and fruit-to-solvent ratio of 1:5.29). The extract obtained in SCW optimum conditions was put under thermal treatments including low temperature long time, high temperature short time, cooking, baking, and sterilization. The results showed after baking, the amount of TPC, RSC, and absorbance at $420 \mathrm{~nm}$ increased. The quantity of gallic acid, chlorogenic acid, p-coumaric acid, ferulic acid, and rutin increased significantly. The efficiency of SCW extract in retarding lipid oxidation in bulk oil and O/W emulsion model was investigated at $50{ }^{\circ} \mathrm{C}$ for 10 days. After 10 days, the peroxide value of bulk oil $\left(1.1 \mathrm{meq} \mathrm{O}_{2} / \mathrm{kg}\right)$ containing SCW extract was lower than $\mathrm{O} / \mathrm{W}$ emulsion model $\left(2.2 \mathrm{meq} \mathrm{O}_{2} / \mathrm{kg}\right)$.
\end{abstract}

Conclusion: The subcritical extracted phenolic compounds seem to have good antioxidant activity as well as thermal stability for using in food or drug industries.

Keywords: Lipid oxidation, Polyphenols, Rhamnus jujuba, Thermal process, Subcritical water

\section{Background}

Adding antioxidants to foods is a technique to reduce lipid oxidation. Antioxidants scavenge free radicals and then inhibit or delay the oxidation of lipid or other molecules [1]. Recently, there has been a considerable interest in removal of synthetic antioxidant and replacing naturally occurring ones due to consumer

\footnotetext{
${ }^{*}$ Correspondence: r.niazmand@rifst.ac.ir

${ }^{1}$ Department of Food Chemistry, Research Institute of Food Science

and Technology, Mashhad, Iran

Full list of author information is available at the end of the article
}

preference for natural and safe products. Natural antioxidants should satisfy several requirements before being accepted for application in food industries. The antioxidant should be resistant to heat processing and effective at a temperature between 25 and $30{ }^{\circ} \mathrm{C}$ for more than a year in order to protect the finished product. Many factors like food moisture, atmospheric oxygen, and high temperatures could create various chemical changes and loss of antioxidants [2]. Polyphenols are one of the widely naturally occurring groups of antioxidants that benefit human health. These compounds act as anti-inflammatory agent, antifeedant, 
phytoalexin and prevent the agent against ultraviolet and inhibit the progression of atherosclerosis and cancer $[1,3,4]$.

Jujube (Ziziphus spp.), also called Rhamnus, has long been cultivated in Iran. It belongs to Rhamnaceae family and contains 40 species. The jujube fruit is considered because of its nutritional and medicinal value. Choi et al. [5] observed a 1.2-2.4 g/100 g dry weight of total phenolic compounds in the pulp of Korean jujube. Seven phenolic compounds including catechin, caffeic acid, epicatechin, ferulic acid, rutin, $p$-hydroxybenzoic acid, and chlorogenic acid were isolated from the jujube fruit by San and Yildirim [6].

The common methods of phenolic compounds extraction are based on solid-liquid extraction by organic solvents. However, these techniques are time-consuming and result in low yields of extraction and use large amounts of organic solvents and solvent residues in the extract [7]. In order to overcome these advantages and access to high-quality extracts, new methods have been developed. Subcritical water (SCW) extraction has been considered for phenolic compounds extraction as a potentially attractive and environmentally friendly method $[8,9]$. SCW uses hot water under pressure enough to retain water in a liquid state. The critical temperature and pressure of water are $374{ }^{\circ} \mathrm{C}$ and $22.1 \mathrm{mPa}$, respectively $[9,10]$. Under subcritical conditions, the hydrogen and hydroxide ions change due to breakdown of intermolecular hydrogen bonds, and dielectric constant of water decreases from 80 to 27 at room temperature and $250{ }^{\circ} \mathrm{C}$, respectively [8, 9], making a desirable medium for the extraction of different natural and bioactive compounds. Several studies have reported utilizing SCW for natural antioxidant extraction from various plants like Moringa oleifera leaf [11], Physalis angulata leaf [12], Bilberry [13], turmeric [14], coriander [15], Crocus sativus petals of saffron industry residues [10], olive fruit dreg [16], marigold flower residues [17], onion [18], and sea buckthorn leaves [19].

To the best of our knowledge, no study has been conducted on SCW extraction of polyphenol from jujube (Ziziphus Jujuba Miller) fruit. Therefore, the present work was conducted to extract phenolic compounds from Iranian jujube by SCW under various operation parameters and optimizing them by response surface methodology (RSM) models. Also, the study was set to investigate the ability of extract obtained in optimized SCW conditions in food industry applications. For this purpose, we evaluate the thermal stability of phenolic compounds after common food heating treatments.

\section{Materials and methods \\ Materials}

Ripe jujube fruits (initial moisture content: $3.78 \pm 0.36 \%$, protein: $2.13 \pm 0.09 \%$, sugar: $20.68 \pm 1.72 \%$, fat: $0.19 \pm 0.08 \%$, ash: $15.19 \pm 5.80 \%)$ were collected from a research orchard in Birjand (Southern Khorasan, Iran). They were washed, depitted, and placed in plastic bags and stored in a freezer $\left(-20{ }^{\circ} \mathrm{C}\right)$ until analyses. Chloroform was purchased from Samchun CO. (Korea) and isooctane was obtained from Lobal Chemie (India). All other chemicals and solvents (analytical and HPLC grades) were purchased from Sigma Aldrich (Gillingham, Dorset, U.K.) and Merck companies.

\section{SCW extraction}

SCW extraction was carried out in a batch-type reactor (model 2009, Research Institute of Food Science and Technology, Mashhad, Iran). The reactor is composed of a stainless steel cylindrical extraction cell with an internal diameter of $32.34 \mathrm{~mm}$, the length of $117.84 \mathrm{~mm}$, and a capacity of $140 \mathrm{ml}$. This apparatus consists of a deionized water feed tank, a high-pressure metering pump (Comet type: MTP AX 2/70m) to deliver water through the system, a pre-heater, a ferro-nickel heating coil wrapped around the extraction cell to provide the required temperature, a pressure gauge (DPI \#104, Groby, Leicestershire, UK), a digital temperature controller (Abtin Mfg Eng CO, Iran), and a cooling system made of stainless steel tubing and chilled with water.

Milled jujube fruits with mean particle size of $0.552 \mathrm{~mm}(5 \mathrm{~g})$ were placed in the pressure-tight cell and distilled water $(15,22.5$, and $30 \mathrm{ml}$ for fruit-to-solvent ratios of 1:3, 1:4.5, and 1:6 W/V, respectively) was added. To preclude plugging, glass wool was put at both ends of the extraction cell. Before each experiment, an extraction cell heat-up was performed for the given times of 5,9 , and 14 min to attain temperatures of 110,140 , and $170{ }^{\circ} \mathrm{C}$, respectively. The reactor was tightly closed under nitrogen gas and placed in a heating mantle. The pressure of the system was adjusted to the desired operating condition (60 bar) using the back-pressure regulator. After extraction, the reactor was removed from the mantle and put in a cool water bath $\left(25^{\circ} \mathrm{C}\right)$. SCW extracts were filtered (by Whatman paper no. 1) and dried at $35{ }^{\circ} \mathrm{C}$ under vacuum and stored in a freezer $\left(-18^{\circ} \mathrm{C}\right)$ for further experiments [10]. Milled jujube fruit-to-the solvent ratio $(1: 3,1: 4.5$, and $1: 6 \mathrm{~W} / \mathrm{V})$, extraction time $(15,45$, and $75 \mathrm{~min})$ and temperature $\left(110,140\right.$, and $\left.170{ }^{\circ} \mathrm{C}\right)$ were investigated according to the variables predicted from the RSM design (Table 1). 


\section{Total phenolic content (TPC)}

TPC was determined by the Folin-Ciocalteu method as described by Ahmadian et al. [20] with slight modifications. The extracts were diluted tenfold with distilled water. Then, $40 \mu \mathrm{l}$ of dilution was mixed with $3.16 \mathrm{ml}$ of distilled water, $200 \mu \mathrm{l}$ of Folin-Ciocalteu reagent, and $600 \mu \mathrm{l}$ of $25 \% \mathrm{Na}_{2} \mathrm{CO}_{3}$. After $30 \mathrm{~min}$ of incubation at room temperature in the dark, the absorbance of the mixture was determined at $763 \mathrm{~nm}$ by UV-Vis spectrophotometer (Shimadzu UV160A, Japan). The calibration curve was plotted with different gallic acid concentrations. TPC was expressed as milligram gallic acid equivalents (GAE) per gram dried extract.

\section{DPPH radical scavenging capacity $\left(\mathrm{RSC}_{\mathrm{DPPH}}\right)$}

The DPPH radical scavenging of extracts was evaluated according to Mousavi and Niazmand [21,22] with a little modification. $500 \mu \mathrm{l}$ of SCW extracts was added to $4 \mathrm{ml}$ DPPH methanol solution $(0.06 \mathrm{mmol} / \mathrm{l})$ and allowed to react for $30 \mathrm{~min}$ at room temperature. The absorbance of the solution was determined at $517 \mathrm{~nm}$. $\mathrm{RSC}_{\mathrm{DPPH}}$ was calculated according to the Eq. 1:

$$
\operatorname{RSC}(\%)=\frac{\mathrm{AC}-\mathrm{AS}}{\mathrm{AC}} \times 100,
$$

where AC and AS are absorbance of the control (methanol) and sample, respectively.

\section{Total flavonoid content (TFC)}

Evaluation of TFC was performed based on the calorimetric method [23, 24]. So, $0.5 \mathrm{ml}$ of extract was mixed with $2.5 \mathrm{ml}$ distilled water and $150 \mu \mathrm{l}$ of a $5 \% \mathrm{NaNO}_{2}$. After standing for $6 \mathrm{~min}, 300 \mu \mathrm{l}$ of $10 \% \mathrm{AlCl}_{3}$ was added to the mixture. The mixture was allowed to stand for $5 \mathrm{~min}$ and then $1 \mathrm{ml}$ of $\mathrm{NaOH}(1 \mathrm{~mol} / \mathrm{l})$ and then $550 \mu \mathrm{l}$ distilled water was added to it. After 5 min standing, the absorbance of the mixture was measured at $430 \mathrm{~nm}$. Quercetin was used as the standard compound. All values were expressed as milligram of quercetin equivalents per gram of extract.

\section{Thermal stability determination}

Five common thermal treatments were utilized as Davidov-Pardo et al. [3] to simulate food industry heating processes. The extracts obtained in SCW optimized conditions were put in hermetically closed glass bottles to be subjected to different heating treatments. After heating, the samples were placed in an ice bath and their volumes were restored to initial to compensate the solvent loss. The conditions of heating treatments were as follows:
Low-temperature long time (LTLT) and high-temperature short time (HTST) pasteurizations: the extracts were kept in a water bath at $65 \pm 2{ }^{\circ} \mathrm{C}$ for $30 \mathrm{~min}$ and $75 \pm 1{ }^{\circ} \mathrm{C}$ for the $20 \mathrm{~s}$, respectively.

Cooking: the extracts were put in a water bath at $93 \pm 2{ }^{\circ} \mathrm{C}$ for $30 \mathrm{~min}$.

Baking: the extracts were put in hermetic closed stainless steel cell with $3.46 \mathrm{~mm}$ internal diameter and $14.20 \mathrm{~cm}$ length and then baked in the oven (Behdad CO. Iran) at $180^{\circ} \mathrm{C}$ for $90 \mathrm{~min}$.

Sterilization: the extracts sterilized in water bath pressure autoclave (RT-2 model, Reyhan Teb, Iran) at $120{ }^{\circ} \mathrm{C}$ for $20 \mathrm{~min}$.

\section{Peroxide value (PV)}

PV was measured according to the spectrophotometric method [25]. The absorbance of the sample was determined at $500 \mathrm{~nm}$ against a blank that contained all the reagents except the sample. The iron (III) chloride solution was used as the standard curve. The PV, expressed as milli-equivalents of peroxide per kilogram $\left(\mathrm{meq} \mathrm{O}_{2} / \mathrm{kg}\right)$ of sample.

\section{Absorbance at $420 \mathrm{~nm}$ (A420)}

The browning of extracts after submitting to heating conditions was expressed by measuring the absorbance at $420 \mathrm{~nm}$ using UV-Vis spectrophotometer [3].

\section{Quantitative analysis of phenolic compounds}

The identification and quantification of phenolic compounds were performed by HPLC analysis. At first, the extracts were filtered and then were directly injected with $20 \mu \mathrm{l}$ syringe filter into chromatography apparatus (KNAUER smartLine, Germany) equipped with a UV detector set at $280 \mathrm{~nm}$. The separation was made at $27^{\circ} \mathrm{C}$ in a Eurosphere $100 \mathrm{C} 18,5 \mu \mathrm{m}, 4.6 \times 250 \mathrm{~mm}$ column protected with a guard column of the same material. The temperature of both columns was kept at $27{ }^{\circ} \mathrm{C}$. Eluents $\mathrm{A}$ and $\mathrm{B}$ were $6 \mathrm{ml} / \mathrm{l}$ of aqueous perchloric acid (70\%) and methanol, respectively. The flow rate was $1 \mathrm{ml} / \mathrm{min}$ throughout the analysis. The elution program was as follows: from $100 \%$ A to $78 \%$ A in 55 min, from $78 \%$ A to $0 \% \mathrm{~A}$ in $10 \mathrm{~min}$, and finally isocratic for another $10 \mathrm{~min}$. To quantify the observed value, the calibration curves for each compound were plotted using the standards.

\section{Statistical analysis}

Operation conditions of subcritical extraction were optimized using RSM according to the Face Central Composite Design (FCCD). Second-order polynomial equations were used to assess the empirical relationship between independent variables (temperature $(\times 1)$, time $(\times 2)$, and the fruit-to-solvent ratio $(\times 3))$ as Eq. 2 : 
Table 1 Coded and un-coded values of independent variables and the responses of the dependent variables utilized in the face central composite design (FCCD) of the SCW extraction process

\begin{tabular}{|c|c|c|c|c|c|}
\hline \multirow{2}{*}{ Run } & \multicolumn{3}{|l|}{ Independent variables } & \multicolumn{2}{|l|}{ Response } \\
\hline & $\begin{array}{l}R \text { (solvent-to-fruit ratio, } \\
\text { V/W) }\end{array}$ & $t($ time, $\min )$ & $T$ (temperature, ${ }^{\circ} \mathrm{C}$ ) & $\mathrm{TPC}(\mathrm{mg} / \mathrm{g})$ & RSC (\%) \\
\hline 1 & $0(4.5)$ & $1(75)$ & $0(140)$ & 574.67 & 22.39 \\
\hline 2 & $0(4.5)$ & $0(45)$ & $0(140)$ & 563.67 & 31.16 \\
\hline 3 & $0(4.5)$ & $0(45)$ & $0(140)$ & 470.33 & 31.44 \\
\hline 4 & $-1(3)$ & $1(75)$ & $-1(110)$ & 298.67 & 28.98 \\
\hline 5 & $1(6)$ & $1(75)$ & $-1(110)$ & 476.33 & 32.65 \\
\hline 6 & $0(4.5)$ & $0(45)$ & $0(140)$ & 470.67 & 35.35 \\
\hline 7 & $0(4.5)$ & $0(45)$ & $0(140)$ & 499.8 & 32.03 \\
\hline 8 & $1(6)$ & $0(45)$ & $0(140)$ & 486.67 & 23.97 \\
\hline 9 & $1(6)$ & $1(75)$ & $1(170)$ & 999.9 & 48.63 \\
\hline 10 & $1(6)$ & $-1(15)$ & $-1(110)$ & 350.67 & 26.12 \\
\hline 11 & $0(4.5)$ & $-1(15)$ & $0(140)$ & 380.67 & 31.53 \\
\hline 12 & $0(4.5)$ & $0(45)$ & $0(140)$ & 506.67 & 34.79 \\
\hline 13 & $0(4.5)$ & $0(45)$ & $1(170)$ & 999 & 52.8 \\
\hline 14 & $1(6)$ & $-1(15)$ & $1(170)$ & 999 & 24.91 \\
\hline 15 & $-1(3)$ & $-1(15)$ & $-1(110)$ & 299.67 & 23.69 \\
\hline 16 & $-1(3)$ & $0(45)$ & $0(140)$ & 507.67 & 21.27 \\
\hline 17 & $-1(3)$ & $1(75)$ & $1(170)$ & 999.5 & 53.98 \\
\hline 18 & $-1(3)$ & $-1(15)$ & $1(170)$ & 967.67 & 25.19 \\
\hline 19 & $0(4.5)$ & $0(45)$ & $-1(110)$ & 318.67 & 29.66 \\
\hline 20 & $0(4.5)$ & $0(45)$ & $0(140)$ & 462.67 & 31.81 \\
\hline
\end{tabular}

$$
\begin{aligned}
Y= & b_{0}+b_{1} x_{1}+b_{2} x_{2}+b_{11} x_{12}+b_{22} x_{22}+b_{33} x_{23} \\
& +b_{12} x_{1} x_{2}+b_{13} x_{1} x_{3}+b_{23} x_{2} x_{3}+\varepsilon .
\end{aligned}
$$

The range and center point values of independent variables are shown in Table 1. Experimental were analyzed by multiple regression to fit the second-order models to the responses. The design expert software version 7 was used to perform regression analysis and data fitting. The counter plots obtained for TPC and $\mathrm{RSC}_{\mathrm{DPPH}}$ were superimposed to estimate the operating conditions.

\section{Results and discussion Experimental design} The RSM was applied to optimize the operating variables in subcritical extraction based on TPC and $\mathrm{RSC}_{\mathrm{DPPH}}$ as responses. The experimental data were fitted into second-order polynomial equations. The fitted models for expressing TPC and $\mathrm{RSC}_{\mathrm{DPPH}}$ of extracts as a function of actual independent variables are given in Eqs. 3 and 4:

$$
\mathrm{TPC}=-1021.06778+10.73689 T+1.17133 t+15.96000 R
$$

$$
\begin{aligned}
\mathrm{RSC}_{\mathrm{DPPH}}= & 178.27345-3.40272 T-0.26043 t+34.56571 R \\
& +5.65306 E-003 T t-0.032561 T R-0.010628 t R \\
& +0.012534 T^{2}-3.32434 E-003 t^{2}-3.25752 R^{2}
\end{aligned}
$$

Data of thermal treatments and oven test were subjected to analysis of variance (ANOVA) performed using Minitab version 16.2. Significant differences among the means were determined via Tukey's range test $(P<0.05)$. All experiments were carried out in triplicate. where $T, t$, and $R$ imply the temperature, time, and solvent-to-fruit ratio, respectively. The ANOVA for $\mathrm{TPC}$ and $\mathrm{RSC}_{\mathrm{DPPH}}$ of the predicted model is presented in Table 2.

In statistically significant models $(P<0.05)$, high regression coefficient demonstrates the substantial effect of independent variables on the corresponding 
responses. The quality and validity of the predicted models can be confirmed by the coefficient of determination $\left(R^{2}\right)$ and $F$-value $(F)$, respectively. The $R^{2}$ value closer to 1 indicates a higher correlation between experimental and predicted values. The reproducibility of the model is expressed by the coefficient of variation (CV). Lack of fit (LOF) indicates the error of the obtained results. The $P$-value implied that the LOF, relative to the pure error, was not significant $(P>0.05)$. The results of $P$-value and LOF confirmed that the predicted models are not statistically significant and it is adequate for prediction the amount of extracted phenolic compounds and their oxidative activity under the combination of variables value of the operation.

\section{Total phenolic compounds (TPC)}

The results of response surface analysis for the effect of temperature and time of extraction on TPC are shown in Fig. 1a. Increasing the temperature from 110 to $170{ }^{\circ} \mathrm{C}$ at 1:4.5 ratio of fruit:solvent sharply increased the TPC $(P<0.05)$. Our results are in agreement with Zakaria et al. [26]. They obtained maximum phenolic extraction from chlorella sp. Microalgae at $175^{\circ} \mathrm{C}$.

Heating can destroy the cell wall of plants and then facilitate the secretion of compounds [27]. We could not apply temperatures beyond $170{ }^{\circ} \mathrm{C}$ because of limitations in our subcritical apparatus. However, the TPC extraction might begin to decrease due to some phenolic compounds denaturation and degradation. To obtain the highest phenolic content, evaluating appropriate operating conditions is important. Temperature showed a large effect on TPC extracted from jujube. The temperature shows dual impacts on solvent as well as solutes. The temperature impacts on the physical properties of solvent such as viscosity, surface tension and dielectric constant [7].

The solubility of phenolic compounds is affected by their chemical nature as well as the polarity of used solvent [28]. At higher temperatures, the water polarity and thus dielectric constant decreases. The dielectric constant of water at ambient conditions is 80 ; however, it can be decreased to 56 and 27 at a temperature higher than $100{ }^{\circ} \mathrm{C}$ and high enough pressure to maintain the liquid state. Superior mass transfer properties of SCW lead to a high diffusivity and hence higher extraction efficiency. Therefore, the solubility and diffusivity of water are comparable with those of organic solvents without any environmental negative impact. Thus, SCW is a suitable method for extracting various phenolic compounds at a high quantity [29, 30]. Sasaki et al. [31] showed that the lignin in the cell wall of plants decomposed to phenolic compounds at the sub- and super-critical conditions.

The effect of extraction time on TPC is depicted in Fig. 1a. Results revealed that prolonging extraction time up to $15 \mathrm{~min}$ favors the extraction of phenolic compounds, but it was not significant at $170{ }^{\circ} \mathrm{C}$ so that the amount of TPC at extraction times of $45 \mathrm{~min}$ and $75 \mathrm{~min}$ was approximately $999 \mathrm{mg} / \mathrm{g}$. This was almost true of other temperatures as well. Increasing extraction time increases exposure of target compounds to the effective extraction medium which is followed by more penetration of solvent into material and consequently leading to more dissolution and diffusion of solute from the material. Extraction time mostly depends on the extraction temperature and target compounds. Long heating extraction may induce bioactive degradation. Furthermore, it can increase the operational costs of process and energy consumption. Therefore, determining the appropriate extraction time is important [26].

The maximum TPC content was obtained at $170{ }^{\circ} \mathrm{C}$ (>999 mg/g) in all studied extraction times. The surface tension and viscosity of the water decreased at a higher temperature, making water penetrate faster to plant matrix pores. Meanwhile, it contributed to the disruption of the analyte-matrix interactions caused by Vander Waals forces, hydrogen bonding, and dipole attraction, and as a result easier diffusion to liquid phase [32]. Budrat and Shotiprak [33] demonstrated similar findings. They

Table 2 Results of ANOVA for the total phenolic compounds (TPC) and radical scavenging capacity (RSC) of the extract

\begin{tabular}{|c|c|c|}
\hline Parameter & TPC & RSC \\
\hline Model* & $\begin{array}{l}1021.06778+10.73689 T+1.17133 t \\
+15.96000 R\end{array}$ & $\begin{array}{l}178.27345-3.40272 T-0.26043 t+34.56571 R+5.65306 E-003 T t-0.032561 T R \\
-0.010628 t R+0.012534 T^{2}-3.32434 E-003 t^{2}-3.25752 R^{2}\end{array}$ \\
\hline$R^{2}$ & 0.863 & 0.7819 \\
\hline CV\% & 4.68 & 18.96 \\
\hline \multicolumn{3}{|l|}{ Lack of fit } \\
\hline$P$ value & 0.96 & 0.93 \\
\hline Fvalue & 0.3 & 21.26 \\
\hline
\end{tabular}

${ }^{*} R$ : solvent-to-fruit ratio, $T$ : extraction temperature, $t$ : extraction time 
reported that temperatures higher than $150{ }^{\circ} \mathrm{C}$ increased water ionization due to hydrolysis reaction at subcritical conditions leads to the more extraction of phenolic compounds from bitter melon.

In accordance with the concept of SCW, extractions should be performed at the highest temperature, which does not cause degradation of the target compounds. As no loss of TPC was observed at the range of studied temperatures, the optimal temperature for TPC extraction of jujube would be somewhere near $170{ }^{\circ} \mathrm{C}$ and even higher. An increasing trend in TPC was observed with increasing of extraction time (Fig. 1a); however, this increase was insignificant $(P>0.05)$; i.e., the effect of temperature was stronger in phenolic compounds extraction compared to extraction time.

Zekovi'c et al. [15] reported that low temperature $\left(100{ }^{\circ} \mathrm{C}\right)$ for polyphenol extraction of coriander (Coriandrum sativum L.) by SCW caused good extraction on shorter extraction time (10-20 min). Also, they assumed the better polyphenols content obtained at an increased temperature $\left(200{ }^{\circ} \mathrm{C}\right)$ and prolonged extraction time (30 $\mathrm{min})$ as the possible release of bounded polyphenols
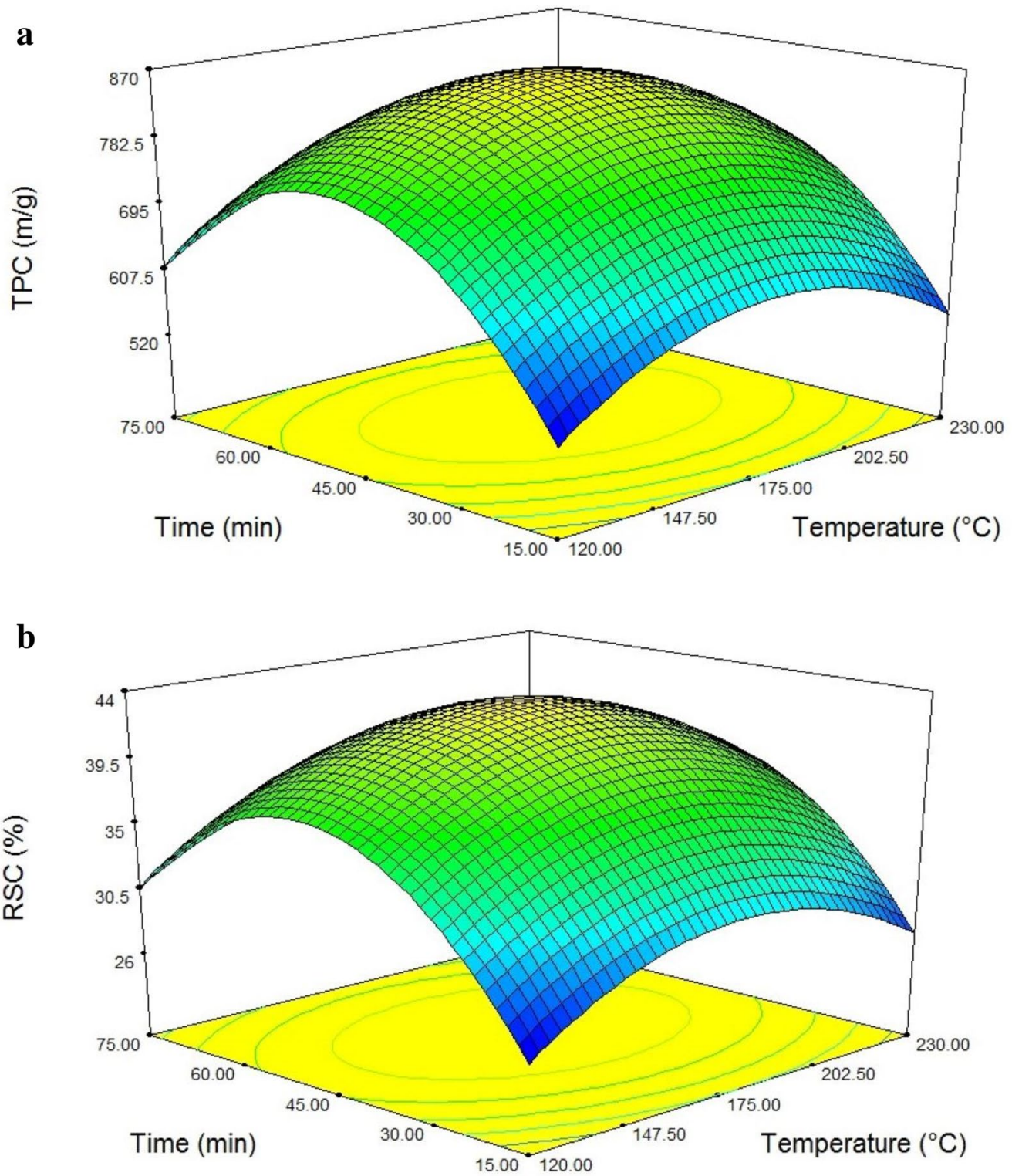

Fig. 1 Response surface plot as simultaneous functions of extraction time and temperature at solvent-to-fruit ratio of 4.5: a total phenolic compounds (TPC), b: radical scavenging capacity (RSC) 
under severe process conditions. These results are consistent with the present findings. Also, they found that increasing of extraction time $(30 \mathrm{~min})$ at $100{ }^{\circ} \mathrm{C}$ caused complete loss of polyphenols.

Figure $2 \mathrm{a}$ shows an increasing trend in TPC with increasing of fruit-to-solvent ratio. The difference of the solutes' concentration between the bulk solution and solvent becomes higher when the solvent-to-fruit ratio increases. Thus, more phenolic compounds can leach out. A lower amount of solvent can lead to incomplete extraction. With increasing the fruit-to-solvent ratio from 1:3 to 1:6, the extraction of TPC would be more complete. However, the effect of fruit-to-solvent ratio on phenolic compounds extraction was not as much as temperature. Muangrat et al. [34] revealed that the total anthocyanin content of dried corn silk samples by SCW extraction at temperature of $100{ }^{\circ} \mathrm{C}$ and extraction time of $15 \mathrm{~min}$ increased with elevating the sample-to-water ratio from 1:4 to $1: 20$, while it decreased with further increasing from 1:20 to 1:24.

\section{Antioxidant capacity}

Most of phenolic compounds are valuable due to their antioxidant activity. According to the results of ANOVA, temperature and time of extraction showed significant effects on $\mathrm{RSC}_{\mathrm{DPPH}}$ (Table 2). The counter curve for the effect of operating conditions on $\mathrm{RSC}_{\mathrm{DPPH}}$ is shown in Fig. 1b. By increasing temperature, especially higher than $140{ }^{\circ} \mathrm{C}$, the $\mathrm{RSC}_{\mathrm{DPPH}}$ increased, indicating that increasing temperature (around $150{ }^{\circ} \mathrm{C}$ ) will cause a reduction in antioxidant activity, probably due to thermal degradation of antioxidant compounds. In comparison, at a higher temperature and harsh extraction conditions, new phenolic compounds may be created with probably more antioxidant activity due to thermal decomposition and browning reactions. However, the amount of $\mathrm{RSC}_{\mathrm{DPPH}}$ increases with a slower trend at longer extraction time. This result is in agreement with Liu et al. [35] who reported no noticeable difference between extraction times more than 30 min during extraction of seed oil from Nitraria tangutorum by the subcritical method. In contrast, according to [32], antioxidant activity in sage (Salvia officinalis L.) extracts increase on elevated extraction time and declined extraction temperature in the presence of acidified water was assumed to release antioxidant agents from plant matrix by acid hydrolysis during the process.

There was an increasing trend in $\mathrm{RSC}_{\mathrm{DPPH}}$ accompanying an increase in a fruit-to-solvent ratio from 1:3 to 1:4.5; the $\mathrm{RSC}_{\mathrm{DPPH}}$ increased significantly, but there was no significant difference in a ratio more than 1:4.5 (Fig. 2b).

Because of antioxidant properties of most phenolic compounds, the antioxidant activity of plant extracts is often connected with TPC. Therefore, the correlation between TPC and RSC was also investigated. The results were fitted to a linear regression (Fig. 3), where no linear correlation was obtained between TPC and RSC $\left(R_{\text {Adjusted }}^{2}=23.3 \%\right)$. Thus, it can be stated that the SCW conditions did not affect, similarly, the TPC and RSC of jujube extract. In other words, increasing the $\mathrm{RSC}_{\mathrm{DPPH}}$ by increasing the extraction temperature is not as much as the TPC. It can indicate that all of the extracted phenolic compounds obtained at a higher temperature may not have anti-oxidation activity.

\section{Optimization}

Optimization regression analysis of SCW conditions influences was studied together with response surface methodology; as it could provide optimization of the process regarding target values of responses. A numerical optimization was carried out to estimate the optimal operating conditions of SCW extraction process. The optimized system aimed to maximize phenolic compound extraction as well as antioxidant activity. The $\mathrm{TPC}$ and $\mathrm{RSC}_{\mathrm{DPPH}}$ were analyzed by allocating the same weight and importance for each compound.

Table 3 gives TPC and $\mathrm{RSC}_{\mathrm{DPPH}}$ of jujube extract at optimum conditions. The correlation between predicted and experimentally observed values of TPC and $\mathrm{RSC}_{\mathrm{DPPH}}$ was determined after preparation of jujube fruit extract at optimized conditions. The optimum conditions predicted by the second-order polynomial model were at fruit-to-solvent ratio of $1: 5.29,170{ }^{\circ} \mathrm{C}$, and $74.49 \mathrm{~min}$ which were verified by experimental results obtained at optimal extraction conditions. The desirability of the model (0.944) expresses that only $5.6 \%$ of responses were beyond the acceptable region.

\section{Thermal stability}

The TPC and TFC of the extract obtained in the optimized condition of SCW after heat treatments are shown in Fig. 4a. The TPC of extract increased after baking (14.1\%); however, it significantly decreased after submitting to other heat treatments $(P<0.05)$. The extracts submitted to the cooking and then LTLT treatments presented the lowest amount of TPC. The temperature affects TPC depending on the amount of temperature and the structure of polyphenol. Some polyphenols degraded during heating and some of them were decomposed to other phenolic components especially with a smaller and basic structure [36, 37]. Xu et al. [17] showed that the total phenolic compounds antioxidant capacity of the of huyou peel extract increase with heating time and temperature. They revealed that after being heated at $120{ }^{\circ} \mathrm{C}$ for $90 \mathrm{~min}$, the TPC increased from 37.33 to 47.20 GAE mg/g of DW by the Folin-Ciocalteu method. 


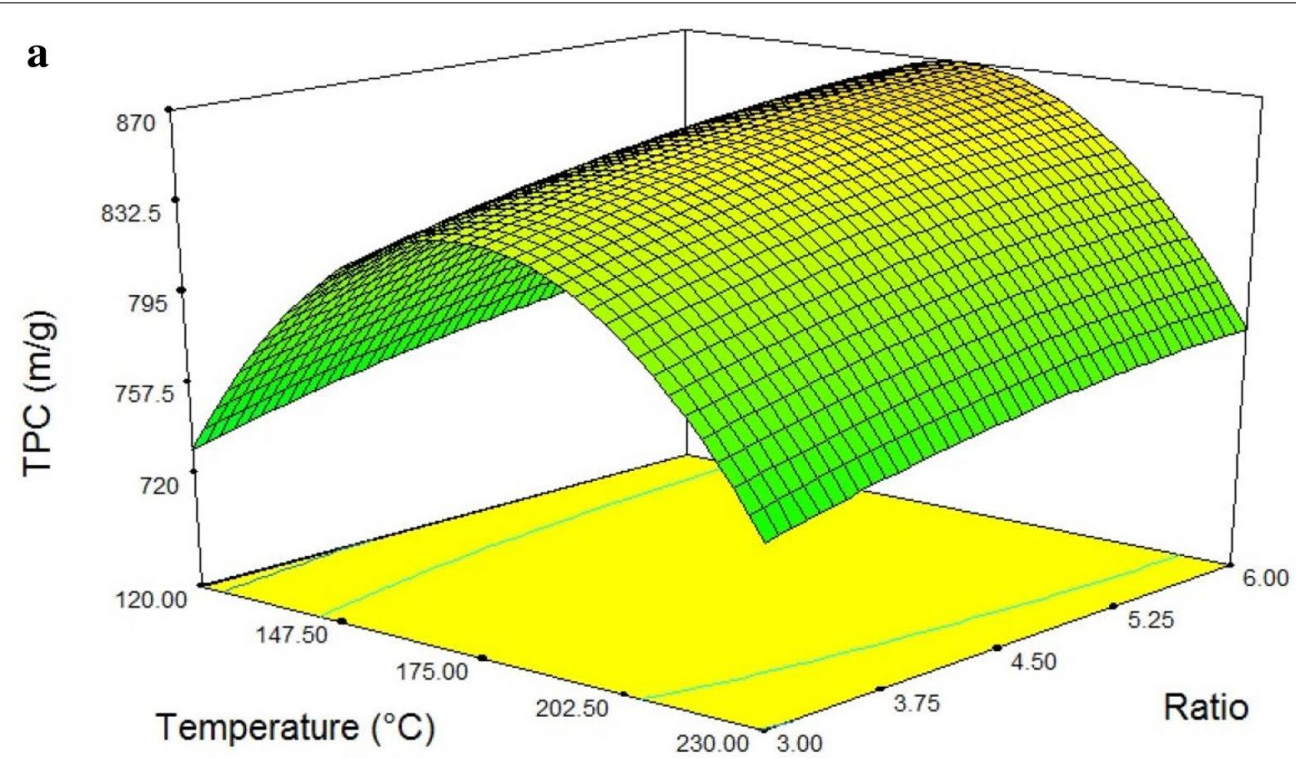

b

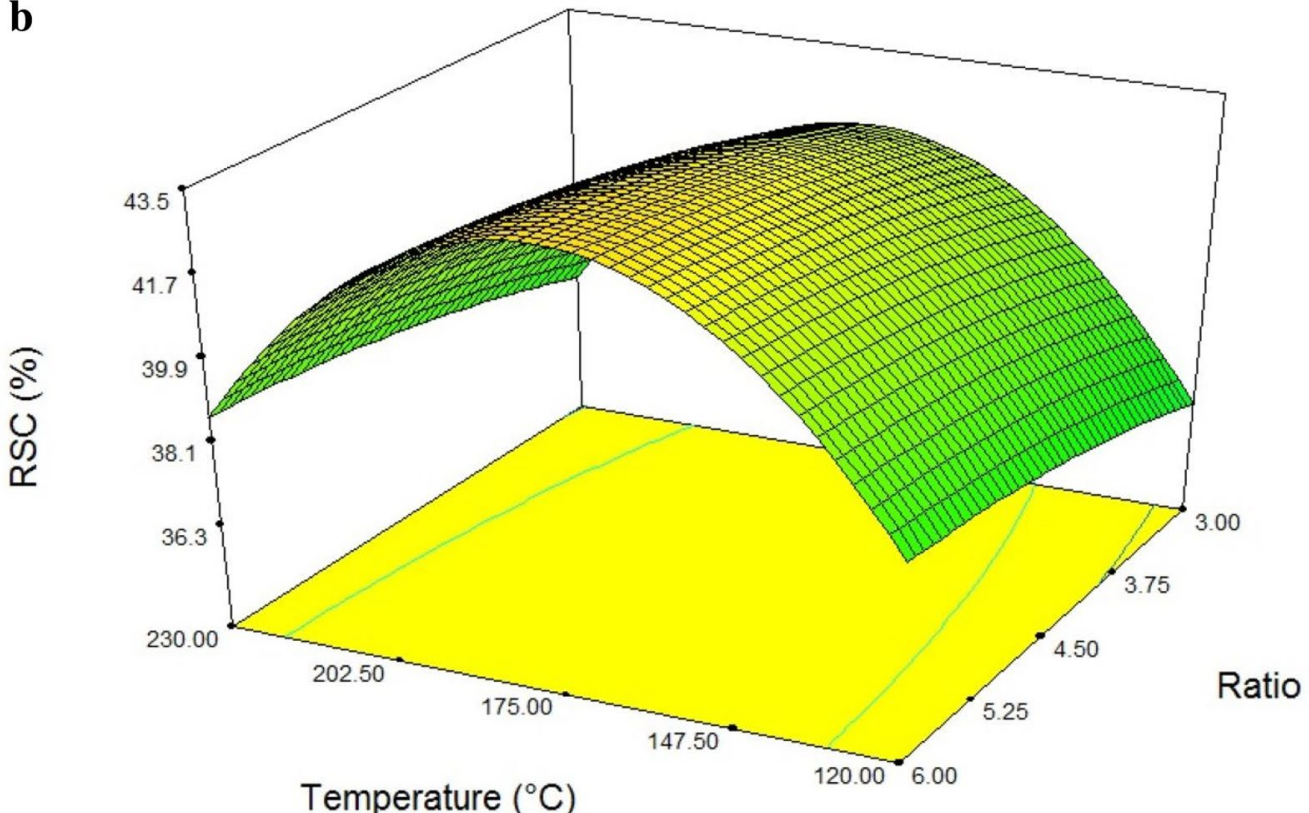

Fig. 2 Response surface plot as simultaneous functions of solvent-to-fruit ratio and temperature at extraction time of 45: a total phenolic compounds (TPC), b radical scavenging capacity (RSC)

Chumyam et al. [38] explained that phenolic content in eggplant cultivars significantly increased when the fruits were heated for 5,10 , or 15 min with boiling, steaming, and microwaving compared with raw fruits possibly due to changing bound phenolic compounds to free forms and releasing into the cytosol.
Table 4 shows the content of individual phenolic compounds identified by HPLC before and after thermal treatments. Gallic acid and rutin presented the highest content of phenolic compounds in extracts. Thermal treatments resulted in a noticeable increase in gallic acid 


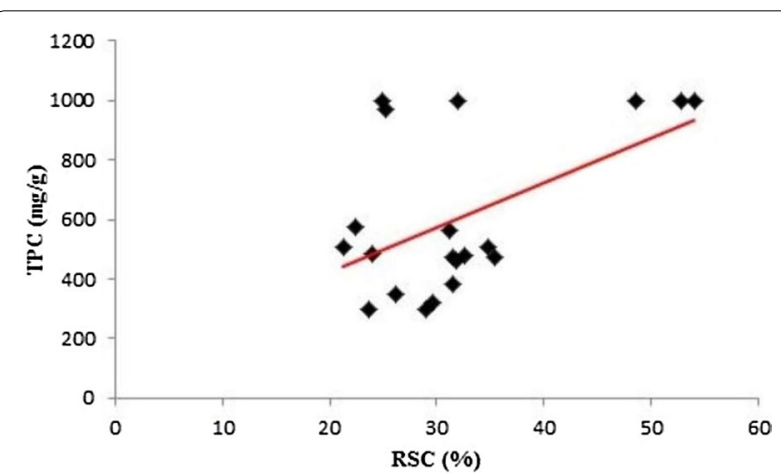

Fig. 3 Correlation between radical scavenging capacity (RSC) and total phenolic compounds (TPC)

and the highest increasing related to the sterilization treatment. Chlorogenic acid, para-coumaric acid, and rutin increased significantly after baking. Sterilization caused the highest reduction in ferulic acid in the extract. The substituted groups on the ring structure play a special role in the decarboxylation of benzoic acid derivatives. Figure 5 reveals the structure of phenolic compounds tested in this study. Khuwijitaru et al. [21] indicated that gallic acid with three hydroxyl groups on its ring decomposed faster than others in subcritical conditions.

In fact, all compounds were degraded as subjected to a thermal treatment; the degraded rate is different for each compound depending on temperature and time. Higher temperature and longer heating time caused a greater decomposition. Decomposition might convert more complex phenolic compounds compared to the basic ones such as gallic acid. Cheng et al. [36] stated that the presence of carboxyl groups in the ring structure facilitates thermal decarboxylation and lack of carboxyl groups and results in a higher thermal stability. The degraded products of phenolic compounds may contain the phenol structure.

The TFC of extracts declined after all thermal treatments, and it was found significant only in the cooked extract $(P<0.05)$. The highest and lowest reduction of TFC were observed in cooked and baked extract equivalent to $20.6 \%$ and $2.2 \%$, respectively. Some compounds such as carotenoids, flavonoids, and lycopene were found to have a great stability through the intense or prolonged heat treatments. In this study, quercetin as one of the flavonoids compounds decreased after all heat treatments.

By comparing the means, it was revealed that baking treatment significantly affected $\mathrm{RSC}_{\mathrm{DPPH}}(P<0.05)$ so that it caused $12.2 \%$ reduction in $\mathrm{RSC}_{\mathrm{DPPH}}$ (Fig. $4 \mathrm{~b}$ ). Despite the decrease in TFC and TPC after heat treatment, $\mathrm{RSC}_{\mathrm{DPPH}}$ exhibited little changes.

A420 of extracts as a browning index is shown in Fig. 4c. The extract with the highest amount of $\mathrm{RSC}_{\mathrm{DPPH}}$ and TPC also showed the highest values on A420; i.e., Millard reaction occurred more and resulted in a darker color. Prolonged or intense heat treatments may result in the formation of Maillard reaction products which generally exhibit strong antioxidant properties [39] and in some cases pro-oxidant activity prior to the Amadori rearrangement. It seems that these reactions partially occurred during SCW extraction due to a high temperature.

\section{Anti-oxidation ability}

ANOVA analysis indicated that the PV of samples significantly changed during oven test $(P<0.05)$. Figure 6a shows that the PV of all bulk oil samples decreased during the second day to the fourth day and after that increased. The control sample and the sample containing $\alpha$-tocopherol trended to sharply increase. The PV of a sample containing BHT gradually increased until the eighth day and increased sharply thereafter. The sample containing extracted phenolic compounds of jujube exhibited the least PV during the storage in the oven. Thus, the efficiency of jujube phenolic compounds was more than that of $\alpha$-tocopherol and BHT to inhibit or delay oil oxidation.

The $\mathrm{PV}$ of all $\mathrm{O} / \mathrm{W}$ emulsion samples increased until the fourth day and then decreased sharply until the sixth day (Fig. 6b), followed by a gradual increase. The results were roughly in contrast to the findings for bulk oil. The emulsion containing extracted phenolic compounds

Table 3 Total phenolic compounds (TPC) and radical scavenging capacity (RSC) of extract obtained by SCW extraction at optimum conditions

\begin{tabular}{|c|c|c|c|c|c|c|}
\hline Source & Ratio & Time (min) & Temperature $\left({ }^{\circ} \mathrm{C}\right)$ & RSC (\%) & $\mathrm{TPC}(\mathrm{mg} / \mathrm{g})$ & Desirability \\
\hline Predicted & 5.29 & 74.49 & 170 & 53.98 & 975.94 & 0.944 \\
\hline Experimental & 5.29 & 74.49 & 170 & 51.81 & 988.50 & - \\
\hline
\end{tabular}



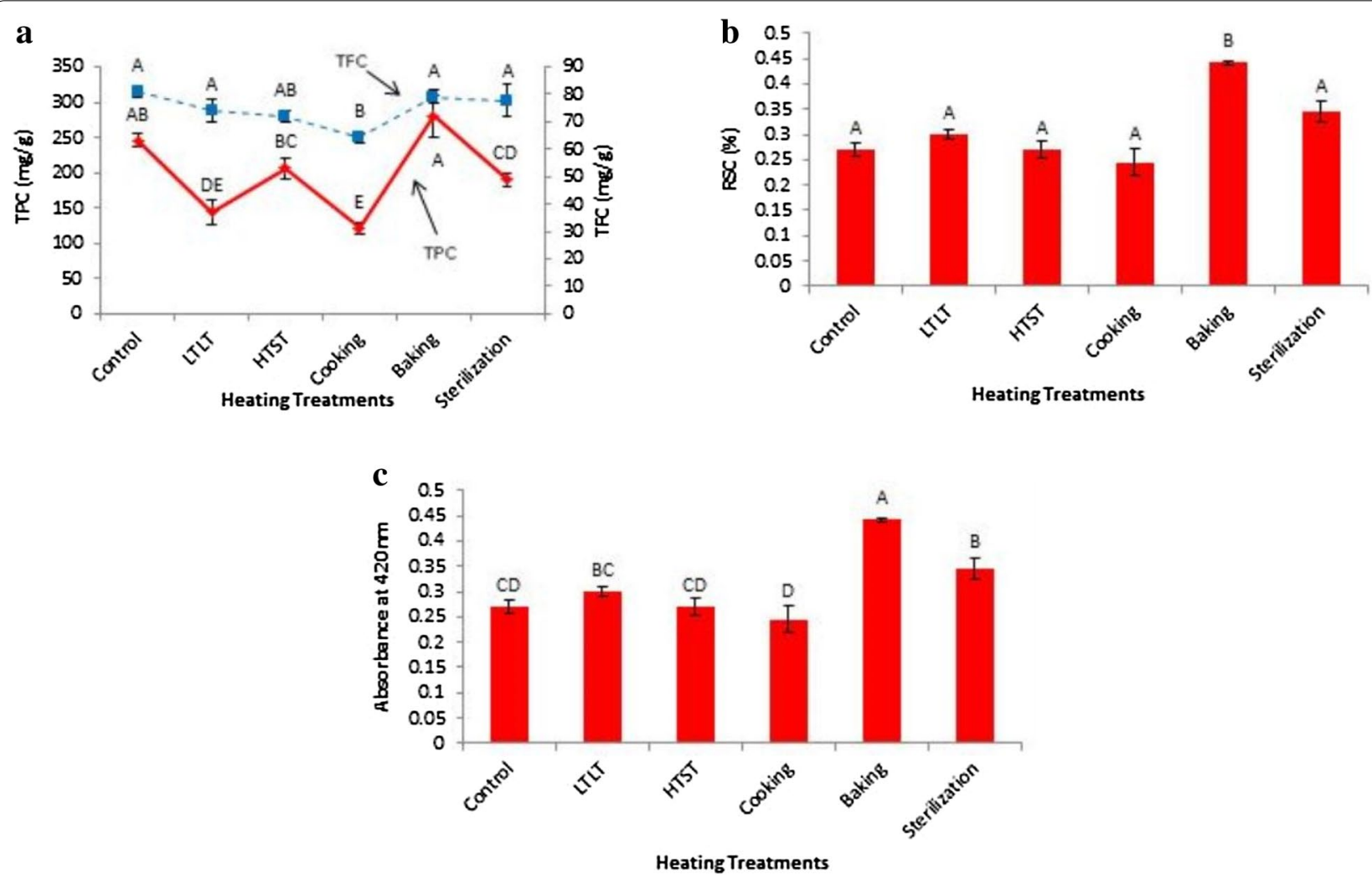

Fig. 4 Characteristics of extract obtained at optimized SCW conditions before and after thermal treatments: a total phenolic compounds (TPC) and total flavonoids compounds (TFC), b radical scavenging capacity (RSC), c absorbance at $420 \mathrm{~nm}$ (A420). Data are mean and SD values. The similar letters show values are not significant at $P<0.05$

Table 4 Individual phenolic compounds ( $\mathrm{mg} / \mathrm{g}$ ) of extract obtained in optimized condition of SCW process (control) and after thermal treatments

\begin{tabular}{lllllll}
\hline Treatment & Quercetin & Rutin & Ferulic acid & para-Coumaric acid & Chlorogenic acid & Gallic acid \\
\hline Control & $0.54 \pm 0.02^{\mathrm{D}}$ & $89.29 \pm 5.18^{\mathrm{A}}$ & $2.41 \pm 0.18^{\mathrm{D}}$ & $0.05 \pm 0.00^{\mathrm{B}}$ & $394.97 \pm 29.81^{\mathrm{A}}$ & $82.17 \pm 5.74^{\mathrm{A}}$ \\
LTLT & $0.17 \pm 0.01^{\mathrm{B}}$ & $83.68 \pm 4.92^{\mathrm{A}}$ & $2.09 \pm 0.21^{\mathrm{D}}$ & $0.03 \pm 0.00^{\mathrm{A}}$ & $383.91 \pm 30.15^{\mathrm{A}}$ & $82.32 \pm 4.98^{\mathrm{A}}$ \\
HTST & $0.27 \pm 0.01^{\mathrm{C}}$ & $86.03 \pm 5.37^{\mathrm{A}}$ & $1.12 \pm 0.15^{\mathrm{C}}$ & $0.08 \pm 0.00^{\mathrm{C}}$ & $395.41 \pm 31.35^{\mathrm{A}}$ & $117.19 \pm 7.26^{\mathrm{B}}$ \\
Cooking & $\mathrm{ND}$ & $86.23 \pm 3.68^{\mathrm{A}}$ & $0.69 \pm 0.08^{\mathrm{B}}$ & $0.08 \pm 0.00^{\mathrm{C}}$ & $399.18 \pm 28.45^{\mathrm{A}}$ & $115.69 \pm 6.72^{\mathrm{B}}$ \\
Baking & $0.24 \pm 0.02^{\mathrm{C}}$ & $137.07 \pm 8.91^{\mathrm{B}}$ & $0.59 \pm 0.06^{\mathrm{B}}$ & $0.13 \pm 0.01^{\mathrm{D}}$ & $526.30 \pm 39.29^{\mathrm{B}}$ & $123.38 \pm 5.34^{\mathrm{B}}$ \\
Sterilization & $0.04 \pm 0.00^{\mathrm{A}}$ & $80.86 \pm 4.25^{\mathrm{A}}$ & $0.19 \pm 0.02^{\mathrm{A}}$ & $0.05 \pm 0.00^{\mathrm{B}}$ & $329.69 \pm 31.28^{\mathrm{A}}$ & $207.73 \pm 8.27^{\mathrm{C}}$ \\
\hline
\end{tabular}

ND not detectable

The similar letters in every column show values are not significant at $p<0.05$

Data are mean and SD values. The data were rounded up to two decimal places

of jujube exhibited the most PV until the 8th day. The samples containing BHT showed the least PV during oven storage. Salcedo and Nazareno [40] used water in oil microemulsion model to investigate the role of walnut and almond phenolic compounds on lipid oxidation. According to their results, depending on the dose, the PV and TBARS values increased in the presence of nuts phenolic compounds.
According to paradox theory, the polar antioxidants are more effective in bulk oil systems. In this regard, in bulk oil, the most oxidation occurs at the air-oil interface where the polar antioxidants are located, whereas the nonpolar antioxidants mix or dissolve in the oil part [41]. 


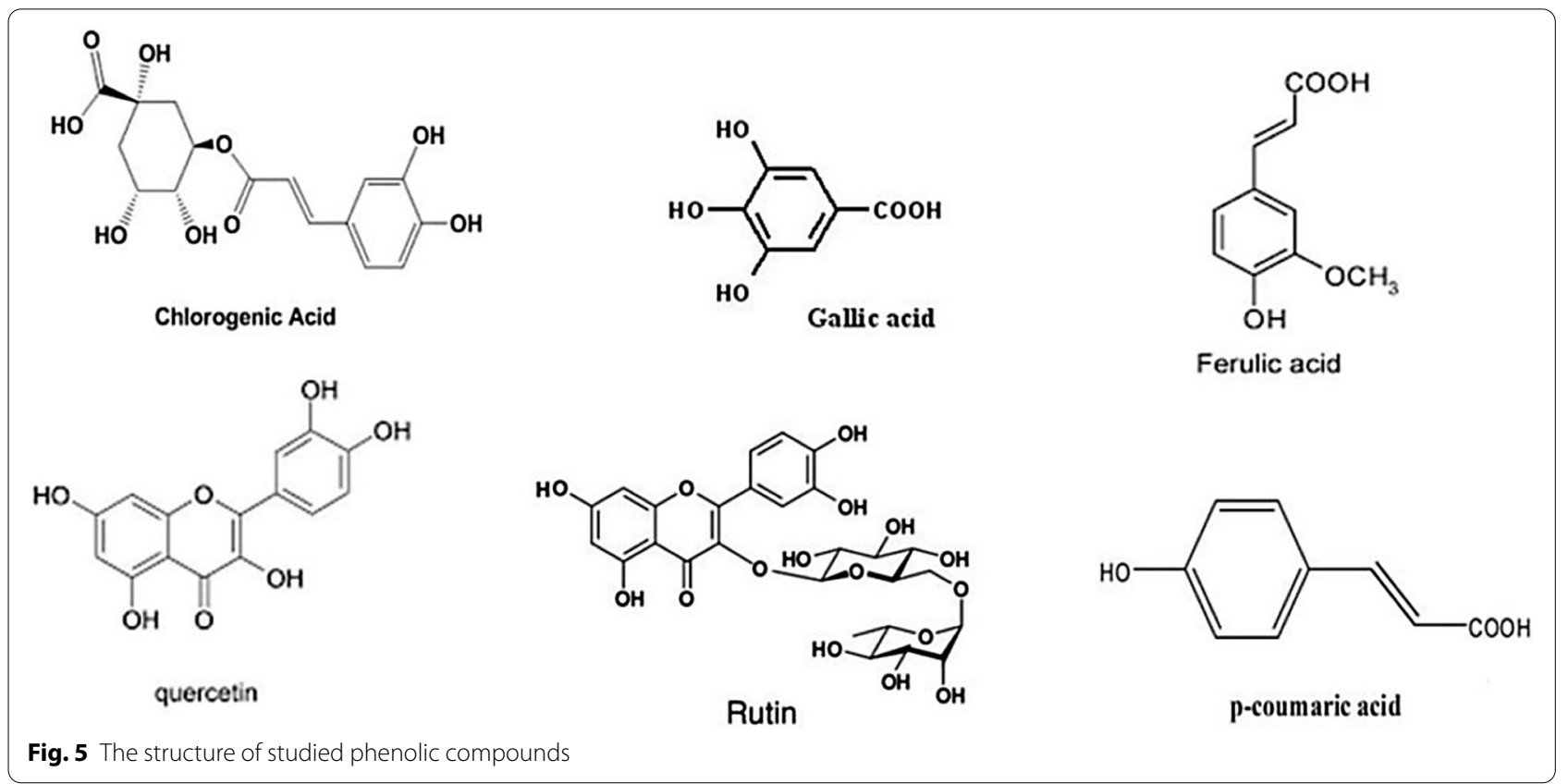

\section{Conclusion}

SCW parameters including fruit-to-solvent ratio, temperature, and residence time were investigated in this study to extract phenolic compounds from jujube. According to the results, the effect of these parameters on TPC and $\mathrm{RSC}_{\mathrm{DPPH}}$ could be predicted through the second-order polynomial equations. The results showed that the main parameter affecting the TPC extract was temperature. In addition, the extraction of phenolic compounds could be achieved in a short residence time (about $75 \mathrm{~min}$ ). SCW extraction as a green and non-flammable technique can be therefore considered on the industrial scale for the nutraceutical and bioactive materials from valuable plants and fruits such as jujube.

Submitting SCW jujube extract to the common thermal treatments decreased the total phenolic content in more cases. However, it did not significantly influence the rate of change in $\mathrm{RSC}_{\mathrm{DPPH}}$ due to changing the phenolic compounds profile as well as chemical properties. Baking exhibited the highest effect on TPC (50.5\%), TFC (20.6\%), and A420 of jujube SCW extract. Although after 10 days, the antioxidant activity of jujube SCW extract against the oxidation was desirable in bulk oil medium (PV: 1.1 meq $\mathrm{O}_{2} / \mathrm{kg}$ ) in comparison with $\alpha$-tocopherol (PV: 2.2 meq $\mathrm{O}_{2} / \mathrm{kg}$ ) and BHT (PV: 2.3 meq $\mathrm{O}_{2} / \mathrm{kg}$ ), it was not effective in $\mathrm{O} / \mathrm{W}$ emulsion.
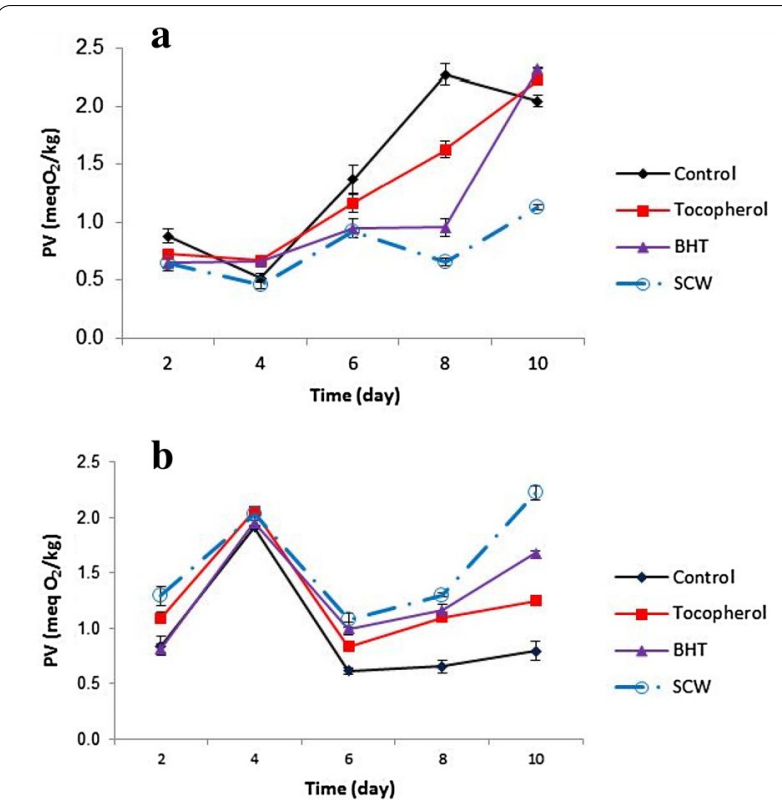

Fig. 6 Peroxide value (PV) of samples containing a-tocopherol, BHT and phenolic compounds of jujube fruit by SCW process: a bulk oil and $\mathbf{b}$ emulsion model. Data are mean and SD values

Accordingly, the phenolic compounds of jujube have enough thermal stability to be utilized in the food industry and processing because of its therapeutic and antioxidant benefits. 


\section{Acknowledgements \\ Not applicable.}

\section{Authors' contributions}

Conceptualization, methodology, formal analysis, English writing and review of the final manuscript were done by RN; investigation, resources and writing were done by MS; statistical analysis and demonstration by AN. All authors read and approved the final manuscript.

\section{Funding}

There was no funding.

\section{Availability of data and materials}

The dataset supporting the conclusions of this study and the information about the materials used is included within the article.

\section{Ethics approval and consent to participate}

Not applicable.

\section{Consent for publication}

Not applicable.

\section{Competing interests}

The authors declare that they have no competing interests.

\section{Author details}

1 Department of Food Chemistry, Research Institute of Food Science and Technology, Mashhad, Iran. ${ }^{2}$ School of Continuing Study, McGill University, Montreal, QC, Canada.

Received: 10 October 2020 Accepted: 1 December 2020 Published online: 21 January 2021

\section{References}

1. Arabshahi-D S, Devi DV, Urooj A. Evaluation of antioxidant activity of some plant extracts and their heat, $\mathrm{pH}$ and storage stability. Food Chem. 2007; 100(3):1100-5.

2. Taghvaei M, Jafari SM. Application and stability of natural antioxidants in edible oils in order to substitute synthetic additives. J Food Sci Technol. 2015:52(3):1272-82

3. Davidov-Pardo G, Arozarena I, Marín-Arroyo MR. Stability of polyphenolic extracts from grape seeds after thermal treatments. Eur Food Res Technol. 2011;232(2):211-20

4. Volf I, Ignat I, Neamtu M, Popa VI. Thermal stability, antioxidant activity, and photo-oxidation of natural polyphenols. Chem Pap. 2014:68(1):121-9.

5. Choi S-H, Ahn J-B, Kozukue N, Levin CE, Friedman M. Distribution of free amino acids, flavonoids, total phenolics, and antioxidative activities of jujube (Ziziphus jujuba) fruits and seeds harvested from plants grown in Korea. J Agric Food Chem. 2011;59(12):6594-604.

6. San B, Yildirim AN. Phenolic, alpha-tocopherol, beta-carotene and fatty acid composition of four promising jujube (Ziziphus jujuba Miller) selections. J Food Compos Anal. 2010;23(7):706-10.

7. Vladić J, Canli O, Pavlić B, Zeković Z, Vidović S, Kaplan M. Optimization of Satureja montana subcritical water extraction process and chemical characterization of volatile fraction of extracts. J Supercrit Fluids. 2017;120:86-94.

8. Pourali O, Asghari FS, Yoshida H. Production of phenolic compounds from rice bran biomass under subcritical water conditions. Chem Eng J. 2010;160(1):259-66

9. Singh PP, Saldaña MD. Subcritical water extraction of phenolic compounds from potato peel. Food Res Int. 2011:44(8):2452-8.

10. Ahmadian-Kouchaksaraie Z, Niazmand R, Najaf NM. Optimization of the subcritical water extraction of phenolic antioxidants from Crocus sativus petals of saffron industry residues: Box-Behnken design and principal component analysis. Innov Food Sci Emerg Technol. 2016:36:234-44.

11. Wang Y, Gao Y, Ding H, Liu S, Han X, Gui J, et al. Subcritical ethanol extraction of flavonoids from Moringa oleifera leaf and evaluation of antioxidant activity. Food Chem. 2017;218:152-8.
12. Susanti RF Natalia D editors. The effect of filler addition and oven temperature to the antioxidant quality in the drying of Physalis angulata leaf extract obtained by subcritical water extraction. IOP Conference Series: Materials Science and Engineering; 2016: IOP Publishing.

13. Babova O, Occhipinti A, Capuzzo A, Maffei ME. Extraction of bilberry (Vacciniummyrtillus) antioxidants using supercritical/subcritical CO2 and ethanol as co-solvent. J Supercrit Fluids. 2016;107:358-63.

14. Kiamahalleh MV, Najafpour-Darzi G, Rahimnejad M, Moghadamnia AA, Kiamahalleh MV. High performance curcumin subcritical water extraction from turmeric (Curcuma longa L.). J Chromatogr B. 2016;1022:191-8.

15. Zeković Z, Kaplan M, Pavlić B, Olgun EO, Vladić J, Canlı O, et al. Chemical characterization of polyphenols and volatile fraction of coriander (Coriandrum sativum L.) extracts obtained by subcritical water extraction. Ind Crops Prod. 2016;87:54-63.

16. Fang X, Wang J, Hao J, Li X, Guo N. Simultaneous extraction, identification and quantification of phenolic compounds in Eclipta prostrata using microwave-assisted extraction combined with HPLC-DAD-ESI-MS/MS. Food Chem. 2015:188:527-36.

17. Xu H, Wang W, Jiang J, Yuan F, Gao Y. Subcritical water extraction and antioxidant activity evaluation with on-line HPLC-ABTS-+ assay of phenolic compounds from marigold (Tagetes erecta L.) flower residues. J Food Sci Technol. 2015;52(6):3803-11.

18. Lee KA, Kim K-T, Kim HJ, Chung M-S, Chang P-S, Park H, et al. Antioxidant activities of onion (Allium cepa L.) peel extracts produced by ethanol, hot water, and subcritical water extraction. Food Sci Biotechnol. 2014;23(2):615-21.

19. Kumar MY, Dutta R, Prasad D, Misra K. Subcritical water extraction of antioxidant compounds from Seabuckthorn (Hippophae rhamnoides) leaves for the comparative evaluation of antioxidant activity. Food Chem. 2011;127(3):1309-16.

20. Ahmadian Z, Niazmand R, Pourfarzad A. Microencapsulation of saffron petal phenolic extract: their characterization, in vitro gastrointestinal digestion, and storage stability. J Food Sci Technol. 2019:84(10):2745-57.

21. Chanudom L, Bhoopong P, Khwanchuea R, Tangpong J. Antioxidant and antimicrobial activities of aqueous \& ethanol crude extracts of 13 Thai traditional plants. Int J Curr Microbiol Appl Sci. 2014;3(1):549-58.

22. Khuwijitjaru P, Plernjit J, Suaylam B, Samuhaseneetoo S, Pongsawatmanit $\mathrm{R}$, Adachi S. Degradation kinetics of some phenolic compounds in subcritical water and radical scavenging activity of their degradation products. Can J Chem Eng. 2014;92(5):810-5.

23. Mousavi SRJ, Niazmand R. Fatty acids composition and oxidation kinetic parameters of purslane (Portulacaoleracea) seed oil. Agric Res. 2017;6(4):421-6.

24. Zhishen J, Mengcheng $T$, Jianming $W$. The determination of flavonoid contents in mulberry and their scavenging effects on superoxide radicals. Food Chem. 1999:64(4):555-9.

25. Ahmadian-Kouchaksaraie Z, Niazmand R. Supercritical carbon dioxide extraction of antioxidants from Crocus sativus petals of saffron industry residues: optimization using response surface methodology. J Supercrit Fluids. 2017;121:19-31.

26. Jalali Mousavi S, Niazmand R, Shahidi Noghabi M. Antioxidant activity of purslane (Portulaca oleracea L.) seed hydro-alcoholic extract on the stability of soybean oil. J Agric Sci Technol. 2015:17(6):1473-80.

27. Zakaria SM, Kamal SMM, Harun MR, Omar R, Siajam SI. Subcritical water technology for extraction of phenolic compounds from Chlorella sp. microalgae and assessment on its antioxidant activity. Molecules. 2017;22(7):1105.

28. Yang L, Qu H, Mao G, Zhao T, Li F, Zhu B, et al. Optimization of subcritical water extraction of polysaccharides from Grifola frondosa using response surface methodology. Pharmacogn Mag. 2013:9(34):120.

29. Tomšik A, Pavlić B, Vladić J, Cindrić M, Jovanov P, Sakač M, et al. Subcritical water extraction of wild garlic (Alliumursinum L.) and process optimization by response surface methodology. J Supercrit Fluids. 2017;128:79-88.

30. Aliakbarian B, Fathi A, Perego P, Dehghani F. Extraction of antioxidants from winery wastes using subcritical water. J Supercrit Fluids. 2012;65:18-24

31. Rangsriwong P, Rangkadilok N, Satayavivad J, Goto M, Shotipruk A. Subcritical water extraction of polyphenolic compounds from Terminalia chebula Retz. fruits. Sep Purif Technol. 2009;66(1):51-6. 
32. Sasaki M, Goto M. Recovery of phenolic compounds through the decomposition of lignin in near and supercritical water. Chem Eng Process. 2008;47(9-10):1609-19.

33. Pavlić B, Vidović S, Vladić J, Radosavljević R, Cindrić M, Zeković Z. Subcritical water extraction of sage (Salvia officinalis L.) by-products - process optimization by response surface methodology. J Supercrit Fluids. 2016;116:36-45.

34. Budrat P, Shotipruk A. Enhanced recovery of phenolic compounds from bitter melon (Momordicacharantia) by subcritical water extraction. Sep Purif Technol. 2009;66(1):125-9.

35. Muangrat R, Williams PT, Saengcharoenrat P. Subcritical solvent extraction of total anthocyanins from dried purple waxy corn: influence of process conditions. J Food Process Preserv. 2017;41(6):e13252.

36. Liu Z, Mei L, Wang Q, Shao Y, Tao Y. Optimization of subcritical fluid extraction of seed oil from Nitraria tangutorum using response surface methodology. LWT-Food Sci Technol. 2014;56(1):168-74.

37. Cheng Y, Xu Q, Liu J, Zhao C, Xue F, Zhao Y. Decomposition of five phenolic compounds in high temperature water. J Braz Chem Soc. 2014;25(11):2102-7.
38. Horvathova J, Suhaj M, Šimko P. Effect of thermal treatment and storage on antioxidant activity of some spices. J Food Nutr Res (Slovak Republic). 2007.

39. Chumyam A, Whangchai K, Jungklang J, Faiyue B, Saengnil K. Effects of heat treatments on antioxidant capacity and total phenolic content of four cultivars of purple skin eggplants. Sci Asia. 2013;39:246-51.

40. Nicoli M, Anese M, Parpinel M. Influence of processing on the antioxidant properties of fruit and vegetables. Trends Food Sci Technol. 1999;10(3):94-100

41. Salcedo CL, Nazareno MA. Effect of phenolic compounds on the oxidative stability of ground walnuts and almonds. RSC Adv. 2015;5(57):45878-87.

\section{Publisher's Note}

Springer Nature remains neutral with regard to jurisdictional claims in published maps and institutional affiliations.

\section{Submit your manuscript to a SpringerOpen ${ }^{\circ}$ journal and benefit from:}

- Convenient online submission

- Rigorous peer review

- Open access: articles freely available online

- High visibility within the field

- Retaining the copyright to your article

Submit your next manuscript at $\boldsymbol{\nabla}$ springeropen.com 